\title{
The effects of heavy metal concentration on bio-accumulation, productivity and pigment content of two species of marine macro algae
}

\author{
W.A. Anusha D.L. Wickramasinghe ${ }^{1 *}$, Valentine K. Mubiana ${ }^{2}$ and Ronny Blust ${ }^{2}$ \\ ${ }^{1}$ Faculty of Fisheries and Marine Science, Ocean University, Matara Road, Tangalle, Sri Lanka \\ ${ }^{2}$ Laboratory of Ecophysiology, Biochemistry and Toxicology, Department of Biology, University \\ of Antwerp, Groenenborgerlaan 171, 2020 Antwerp, Belgium. \\ *corresponding author: lankadimuthu@yahoo.com
}

\begin{abstract}
Environmental pollution due to heavy metals is a world-wide problem in estuarine, coastal and marine waters. Metal pollution affects different organisms in different ways and the degree of the impact is site-specific. Aim of the present study was to determine the effects of heavy metals viz., $\mathrm{Cu}, \mathrm{Cd}$ and $\mathrm{Pb}$ exposure on tissue accumulation, pigmentation and productivity of two marine macro algae, Fucus vesiculosus and Ulva lactuca under controlled laboratory conditions. Algae were collected from a reference location, Wemeldinge in the Eastern Scheldet Estuary in Netherlands. Metal concentrations were determined using ICP-MS. Productivity of algae was measured using Winkler method and the results were expressed as carbon equivalent. Pigment profiles of two species were analyzed by spectral absorbance over $250-1100 \mathrm{~nm}$ range. The results revealed that the metal accumulation in tissues significantly increased with increasing exposure to metal concentration whereas, pigmentation, and photosynthetic productivity decreased with increasing metal concentration. Hence, F. vesiculosus and U. lactuca could be used as bio-indicators to determine metal pollution in coastal waters.
\end{abstract}

Keywords: heavy metal pollution, Fucus vesiculosus, Ulva lactuca, bio-indicator

\section{INTRODUCTION}

Most countries in the world are presently facing chemical pollution problem severely with increasing industrial activities as well as rapid population growth and daily human activities. Metal pollution in the marine ecosystem due to anthropogenic activities is well documented (De Kock and Kramer 1994; Galloway et al. 2002). Hence, chemical pollutants such as heavy metals and their impacts on the aquatic environment will always be a matter of concern.

Biological monitoring or bio-monitoring is defined as the systematic use of biological responses to evaluate changes in the environment, with a view to establishing a quality control programme (Cairns and van der Schalie 1980). Such bio-monitors should involve relatively inexpensive equipment and methodology that are easy and fast to perform rather than introducing very sophisticated analytical methods using advance technologies and instrumentation that cannot be affordable by most developing countries. Therefore, such an approach may be an alternative method to monitor pollution status of developing countries.

Environmental pollutants originating from diverse anthropogenic sources have been known to possess adverse effects capable of degrading the ecological integrity of marine environment (Torres et al. 2008). In many situations, the consequences of anthropogenic contamination of marine environments have been ignored or poorly identified (Cairns 1982). Monitoring the impact of pollutants on aquatic life forms is challenging due to the differential sensitivities of organisms to a given pollutant, and the inability to assess the longterm effects of persistent pollutants on the ecosystem as they are bio-accumulated at every trophic level (Torres et al. 2008).

Aquatic environments are more susceptible to the harmful effects of heavy metal pollution because aquatic organisms are in close and prolonged contact with the soluble metals (Torres

Sri Lanka J. Aquat. Sci. 22(1) (2017): 1-8 


\section{L.N. Wijewardene et al.}

et al. 2008). Marine macro algae are in particular potential indicator species for organic and inorganic pollutants since they are comparatively more abundant life forms in aquatic environments and occupy the base of the food chain (Torres et al. 2008).

A good choice of a bio-monitor species is an integral part of a successful bio-monitoring programme. Therefore, it is important to select a good candidate with relevant qualities that suit the best general situation of the study environment. For organic xenobiotics, algae play an important role in the dispersal (Wang et al. 1998; Kowalewska 1999), chemical transformation and bioaccumulation of many toxic compounds (Okay et al. 2000; Lei et al. 2002, 2007; Murray et al. 2003).There are special advantages of using marine macro algae as 'sentinel' or 'indicator' organisms in environmental programmes throughout the world.

Many studies have reported uptake of heavy metals by different macro algae (Bryan 1969; Phillips 1990; Leal et al. 1997). Further, macro-algae (seaweeds) have increasingly been used as bio-detectors to monitor xenobiotics in marine environments (Levine, 1984; Stewart, 1995; Whitton and Kelly, 1995). Use of macro algae in bio monitoring studies was limited in 1980 s although marine macro algae have been shown to be good bio-indicators of heavy metal contamination in seawater (Bryan 1983; Soderlund et al. 1988). However, use of marine algae as test organisms in laboratory studies of marine pollution has gradually been increased (Fletcher 1991). Heavy metals may also lead to a decrease in primary productivity of macro-algae.

Therefore, this study was carried out to examine to what extent does the heavy metal exposure impacts on bio-accumulation, primary productivity and pigment content of two species of marine macro-algae.

\section{MATERIALS AND METHODS}

\section{Source of the plants}

Two species of macro-algae, Ulva lactuca (a green alga) and Ficus vesiculosus (a brown alga) were collected from Wemeldinge in the Eastern Scheldt estuary in Netherlands (Fig. 1) and were transported to the laboratory in sea water. In the laboratory, they were further cleaned using clean seawater to remove any sand or other epiphytes and acclimatized for the laboratory conditions for 72 hours.

\section{Exposure medium}

The seawater used in the experiments was prepared from hw Sea Salt by dissolving $35 \mathrm{~g} / \mathrm{L}$ sea salt in deionised water (Wiegandt $\mathrm{GmbH}$, Germany). This artificial sea water was then enriched with nutrients and filtered before use (pore size $0.45 \mu \mathrm{m}$ filter paper).

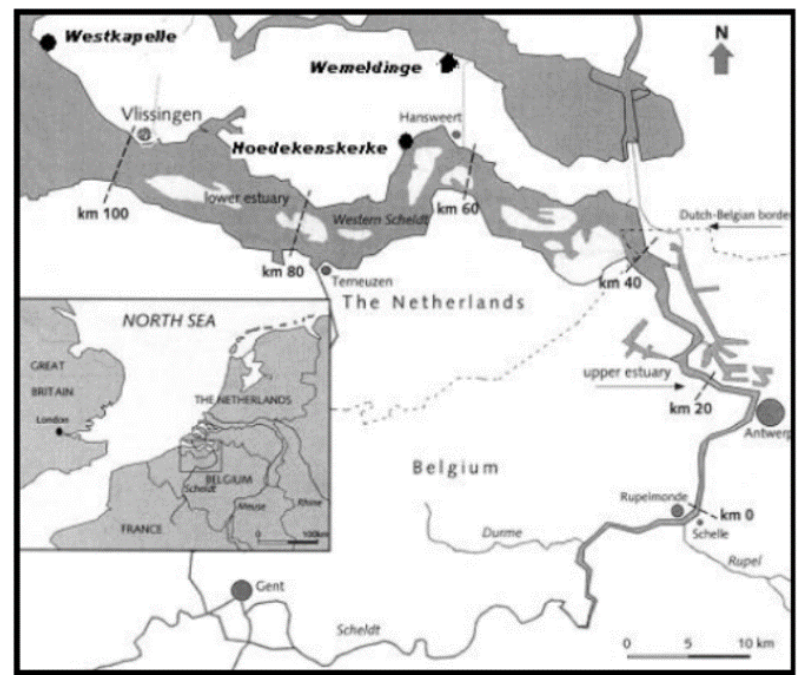

Fig. 1 Sampling location (Wemeldinge) in the Scheldt estuary in the Netherlands.

\section{Metal concentrations}

Test metals mixture (100 $\mu \mathrm{M}$ stock solution) was prepared in the form of high grade chloride salts (for $\mathrm{Cu}$ and $\mathrm{Cd}$ ) and a nitrate salt (for $\mathrm{Pb}$ ) of the metals. These heavy metals were specifically selected in order to have representative metal, $\mathrm{Cu}$ among essential elements whereas $\mathrm{Cd}$ and $\mathrm{Pb}$ represented non-essential elements. To make the metal mixture $\left(100 \mu \mathrm{M}\right.$ stock solution), $\mathrm{CuCl}_{2}$, $\mathrm{CdCl}_{2} \cdot \mathrm{H}_{2} \mathrm{O}$ and $\mathrm{Pb}\left(\mathrm{NO}_{3}\right)$ with the weights of $17.048 \mathrm{mg}, 20.132 \mathrm{mg}$ and $33.12 \mathrm{mg}$, respectively were dissolved in $1 \mathrm{~L}$ of artificial sea water. From this stock solution, the dilutions series of $0.01,0.1$, 1.0 and $10.0 \mu \mathrm{M}$ were prepared (Final concentrations were measured using ICP-MS) by mixing suitable amounts of artificial sea water to give different exposure levels for the organisms during lab experiment. 


\section{L.N. Wijewardene et al.}

\section{Experimental setup}

The experiment was conducted in a climate chamber. Three individual plants from each algal species were placed in each exposure concentrations $\left(0.01,0.1,1.0\right.$ and $\left.10 \mu \mathrm{mol} \mathrm{l}^{-1}\right)$ as well as in clean seawater as control $\left(0 \mu \mathrm{mol} \mathrm{^{-1 }}\right)$, resulting in a total of five treatments for each algae species. Water temperature in all the tanks was maintained at $16( \pm 0.5)^{\circ} \mathrm{C}$. Light was from fluorescence tubes (Philips TLD 38W/840). These light and temperature conditions were chosen as they allowed the most stable conditions in culture for the algae (unpublished data). Also water was constantly aerated with filtered air. After 48 hours first sub sampling was done from each exposure medium as three pieces of each species (one piece from one plant) in order to use in different analyzing procedures i.e. (i) material for metal analysis which was approximately $0.1 \mathrm{~g}$, (ii) material for productivity measurements, approximately $1 \mathrm{~g}$ and (iii) for pigment analysis, approximately $0.01 \mathrm{~g}$. This was repeated after 98 hours and 504 hours for each species.

\section{Primary productivity analysis in marine plants}

Primary productivity of algae (piece) was measured using light and dark bottle method (Gaitán-Espitia 2011 ) in three replicates. The amount of oxygen produced was then converted into the equivalent carbon that the algae incorporated over the same period.

\section{Pigment concentrations analysis in marine plants}

Concentrations of pigments were determined using spectrometric measurements. Firstly, tissue homogenation in liquid nitrogen followed by pigment extractions in acetone. The samples then scanned for spectral absorbance over the range of 350-750 nm wavelengths (the absorbance was read in a spectrophotometer at every $1 \mathrm{~nm}$ or $20 \mathrm{~nm}$ ) with respect to a blank sample (i.e. only acetone) that was used to extract the pigments.

\section{Metal analysis in marine plants}

Fifteen replicates for each species were inserted into certified trace metal-free tubes and oven dried at $60^{\circ} \mathrm{C}$ for 72 hours. After drying, the tissues were weighed to obtain dry tissue weight and digested in concentrated (99\%) $\mathrm{HNO}_{3}$ for at least 12 hours. Samples were then digested by heating in a microwave oven during four consecutive steps i.e. for 8 minutes. Samples of reference materials of algae tissue (BCR-279, Ulva lactuca) were always included with each batch of samples for verification of the measurements. Reagent blanks were also included. After digestion, sample volumes were made up to $12 \mathrm{ml}$ with Milli-Q water.

Metal concentrations in the samples were determined using Inductively Coupled Plasma Mass Spectrometer (ICP-MS) (Varian, Australia) with certified reference samples (BCR-279).

\section{Statistical Analysis}

GraphPad Prism Ver. 5 software was used to make graphs and all statistical analyses. Kruskal-Wallis test was performed for comparisons and to confirm whether the observed result was significant followed by Dunn's Multiple Comparison Post-hoc Test.

\section{RESULTS}

Metal concentrations in both algae species after $48 \mathrm{~h}, 96 \mathrm{~h}$ and $504 \mathrm{~h}$ of exposure to a wide range of concentrations $(0.01-10 \mu \mathrm{M})$ are shown in Figure 2.

As shown in Figure 2, metal accumulation only appeared to increase at exposure concentration above $1 \mu \mathrm{M}$ of metal. Results shown that metal accumulation in the highest exposure $(10 \mu \mathrm{M})$ was significantly higher for both species and for all the three metals studied.

The data was also tested to see if there were differences in accumulations among the three sampling times (48h, 96 and 540h) and the results revealed the levels of metal accumulations at high exposure time were not high enough to be significantly different from the earlier sampling times. 


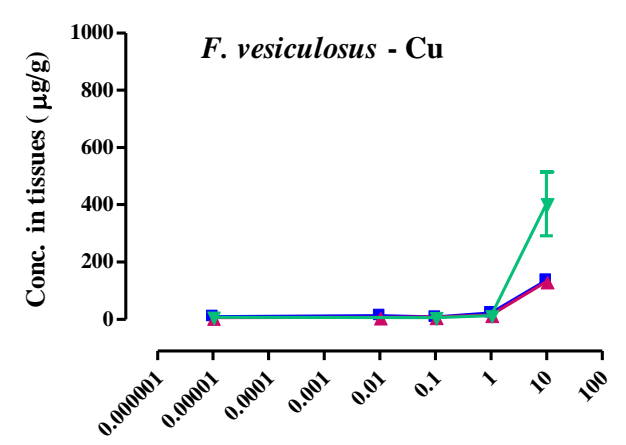

Exposure concentration $(\mu \mathrm{M})$

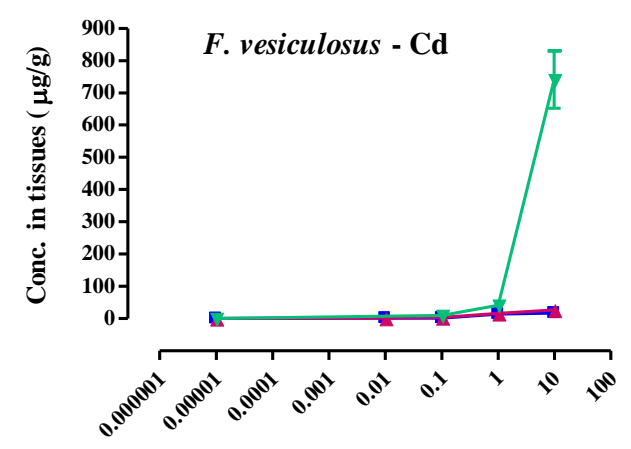

Exposure concentration ( $\mu \mathrm{M})$

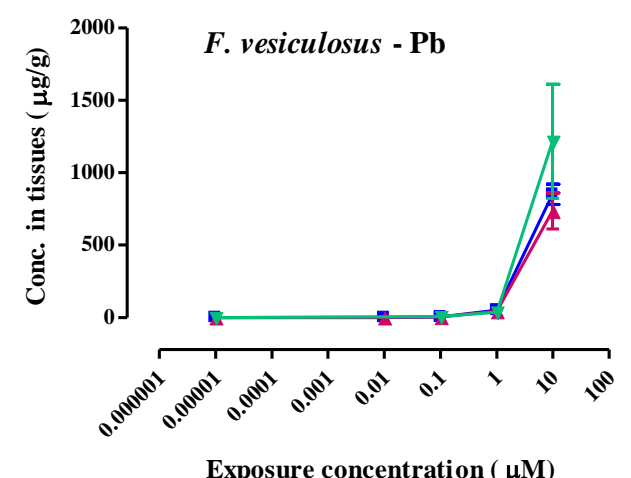

Exposure concentration ( $\mu \mathrm{M})$

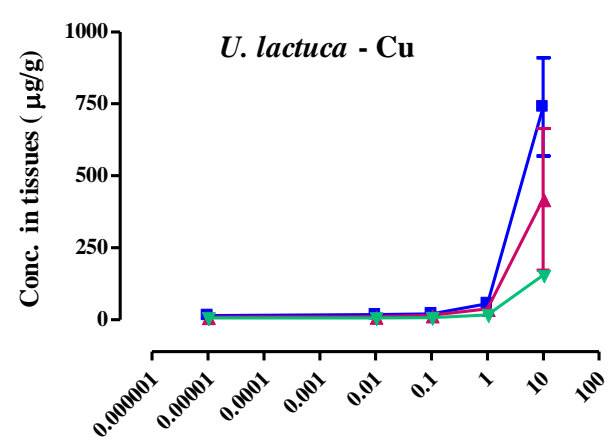

Exposure concentration $(\mu \mathrm{M})$

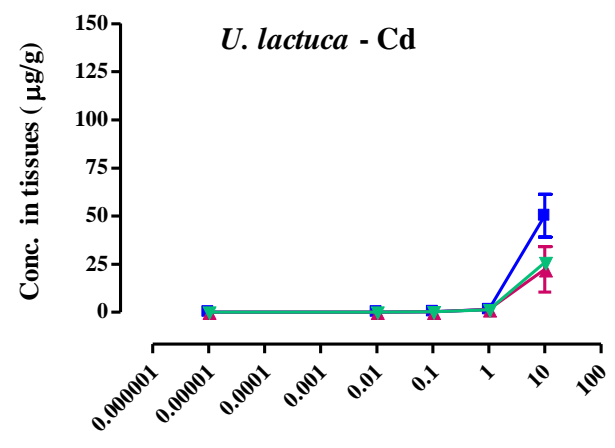

Exposure concentration ( $\mu \mathrm{M})$

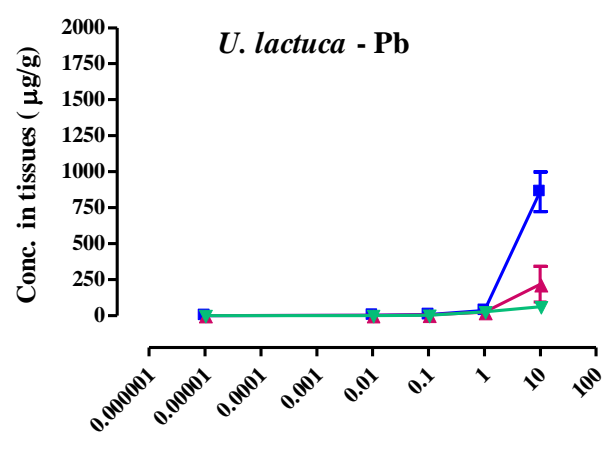

Exposure concentration $(\mu \mathrm{M})$

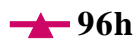

$\checkmark 540 h$

Fig. 2 Net metal accumulations (mean $\pm \mathrm{SD}$ ) in $F$. versiculasis and $U$. lactuca at the range of exposure concentrations for $48 \mathrm{~h}, 96 \mathrm{~h}$ and $540 \mathrm{~h}$. 


\section{L.N. Wijewardene et al.}

Figure 3 shows the mean spectral absorbance between $350 \mathrm{~nm}$ and $750 \mathrm{~nm}$ wavelength for $U$. lactuca and $F$. vesiculosus at three different sampling time periods. Here, the area of the peak
Chlorophyll a, b and c pigment profiles of $F$. vesiculosus and $U$. lactuca are known to contain these pigments between $600-740 \mathrm{~nm}$.
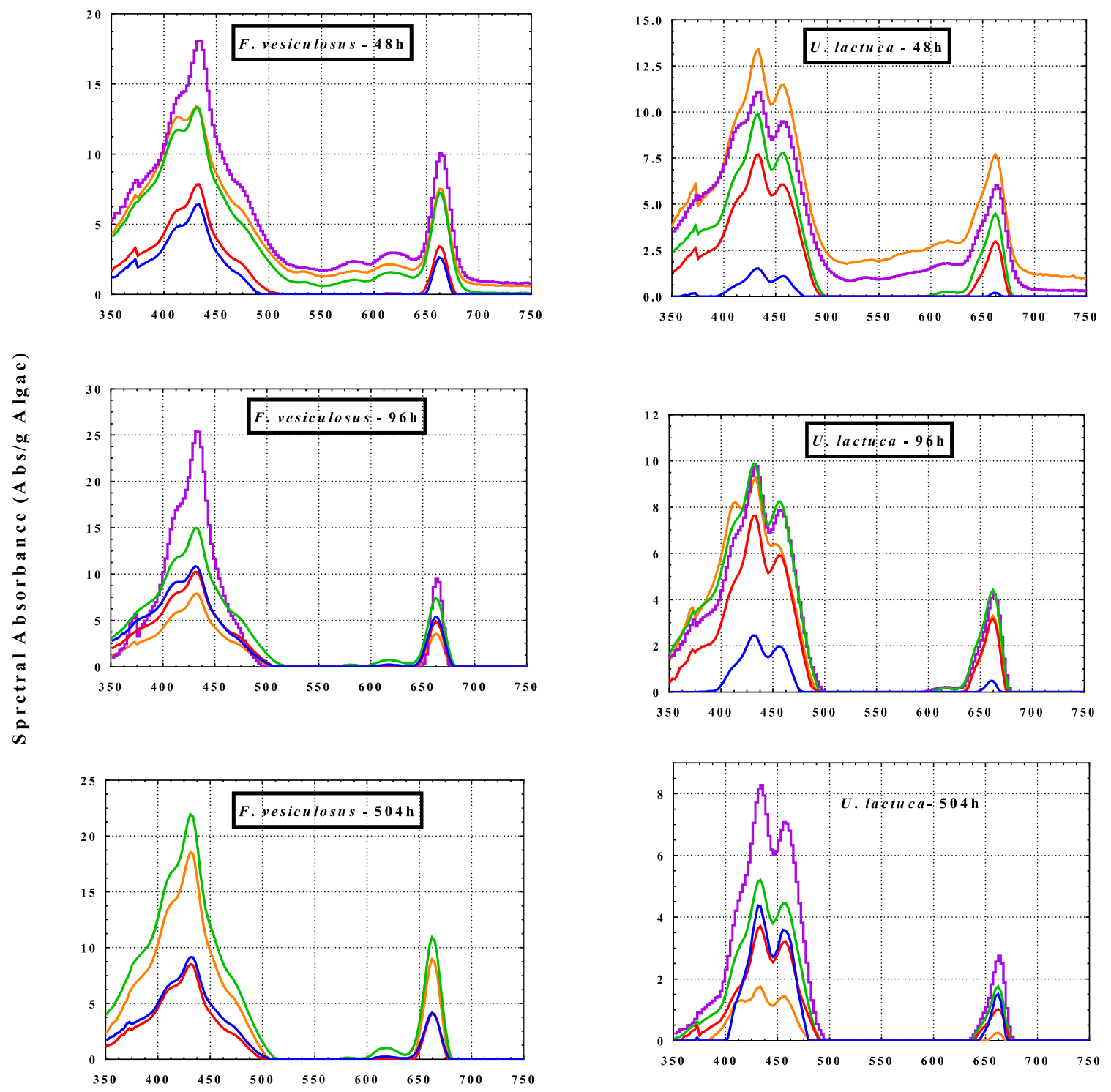

W avelength ( $\mathrm{nm})$
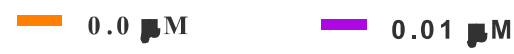

0.1 M

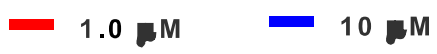

Fig. 3 Differences in pigmentation of U. lactuca and F. vesiculosus after 48h, $96 \mathrm{~h}$ and 504h respectively.

The effects of metal exposure $(\mathrm{Cu}, \mathrm{Cd}$ and $\mathrm{Pb}$ mixture) and time (48h, 96h, and 504h) on primary productivity of $F$. vesiculosus and $U$. lactuca are shown in Figures 4 and 5 respectively. In all exposure concentrations $F$. vesiculosus showed low amount of net productivity than $U$. lactuca. 


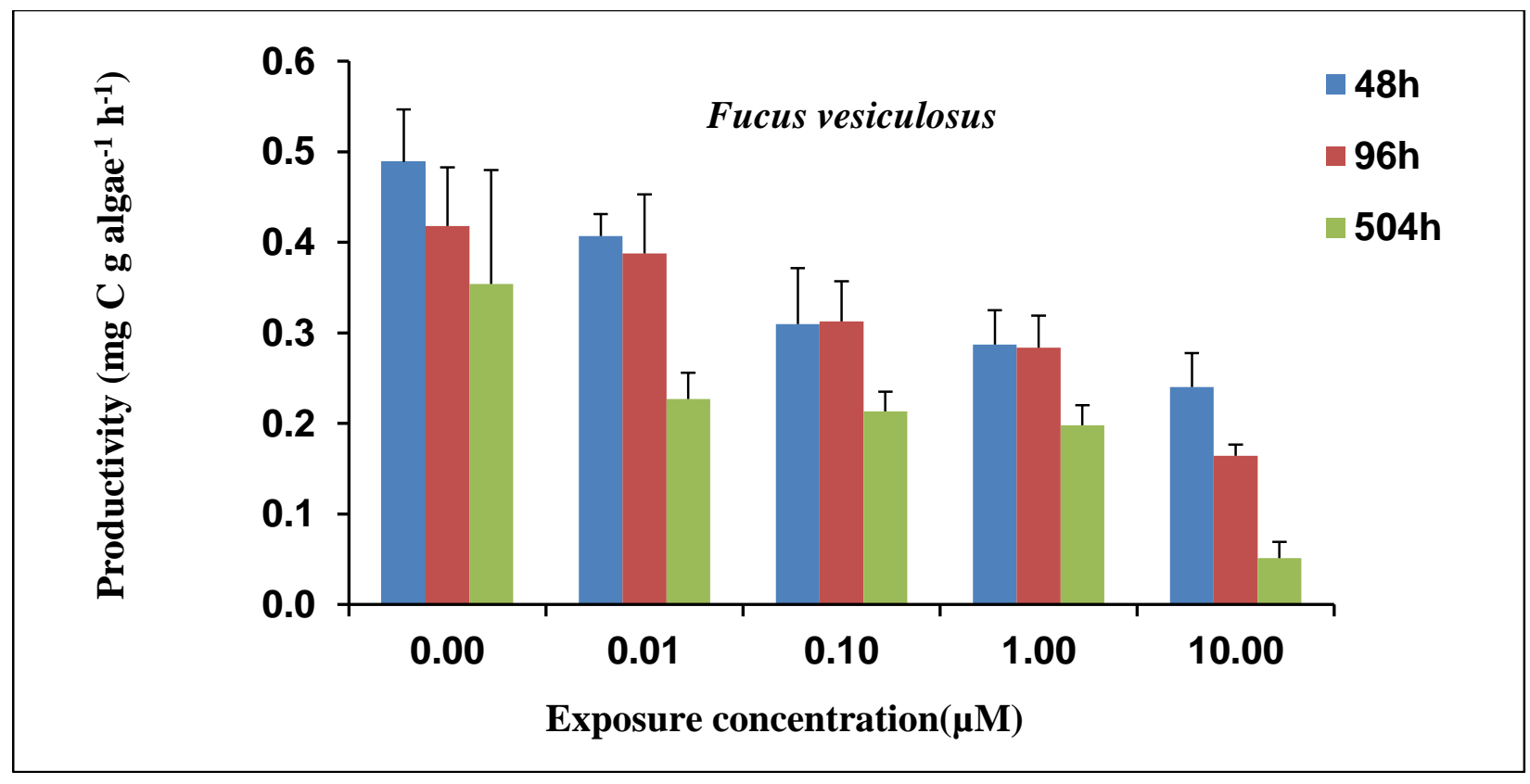

Fig. 4 Productivity (mean $\pm \mathrm{SD}$ in $\mathrm{mg} \mathrm{C/g}$ algae/h) of $F$. vesiculosus at different exposure concentrations $(\mu \mathrm{M})$ and exposure time (hrs)

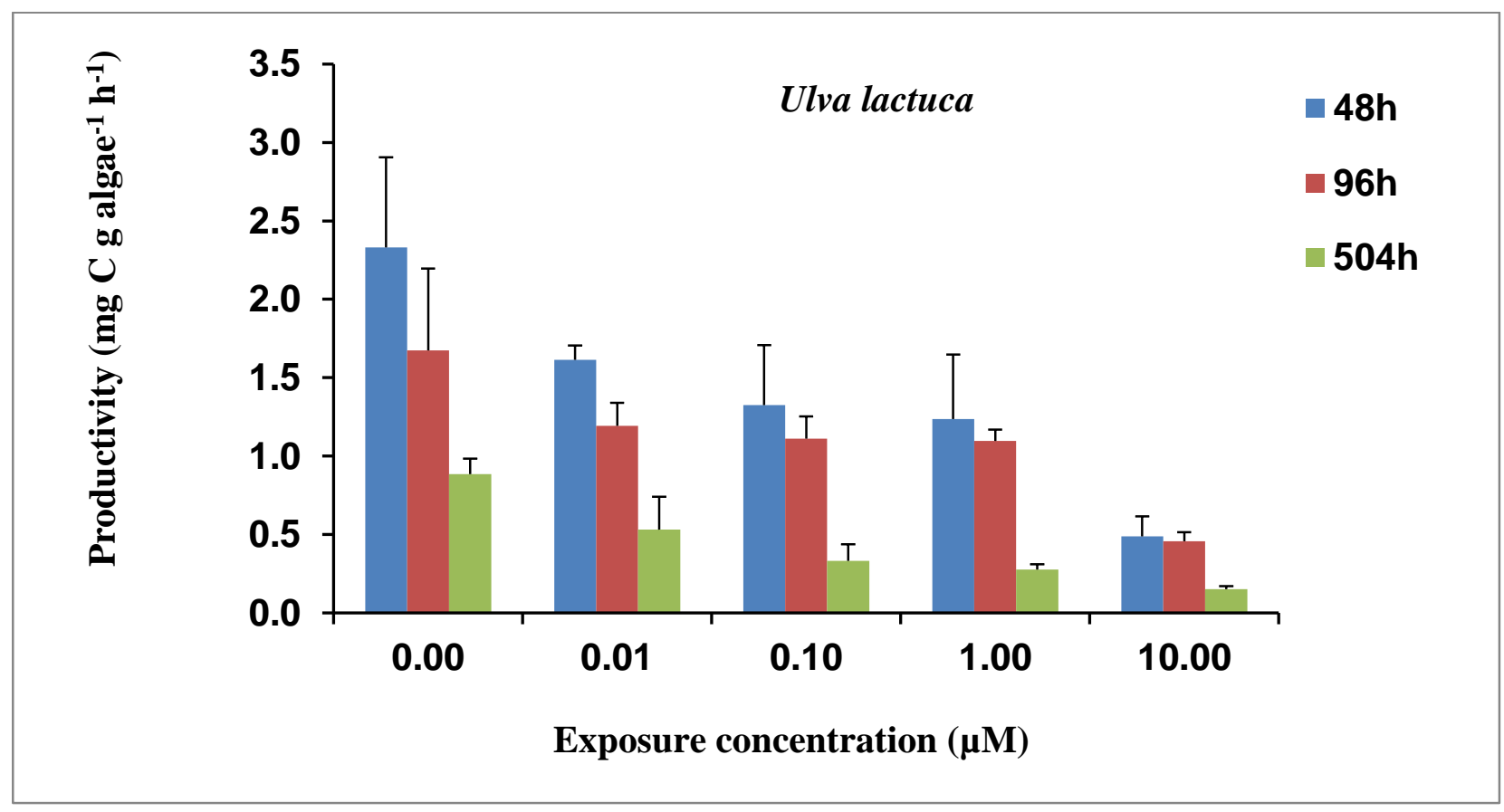

Fig. 5 Productivity (mean $\pm \mathrm{SD}$ in $\mathrm{mg} \mathrm{C/g}$ algae/h) of U. lactuca at different exposure concentrations $(\mu \mathrm{M})$ and exposure time (hrs) 
Kruskal-Wallis test showed that the observed accumulation was significant for all the three metals and also for both species as well as for exposure concentrations. However the results of Post-hoc test (Dunn's Multiple Comparison) showed the metal accumulation was significantly high for both species and for all the three metals at the highest exposure (10 $\mu \mathrm{M})$. Accordingly in order to obtain significant values it is necessary to expose them to the concentrations above $1 \mu \mathrm{M}$.

\section{DISCUSSION}

In order to use pigmentation as a good or potential indicator of environmental pollution, there should a clear indication (by color changing) of deviation of the natural status when it is exposed to metal contaminants. As it can be seen in Figure 3, the pigment profiles are exactly the same but the heights of peaks are proportionately reducing when increasing exposure concentration.

According to Prasad and Strzalka (1999), certain pollutants, such as heavy metals, reduce photosynthesis by affecting the light harvesting complex, oxygen evolution complex, cytochrome complex, plastoquinone, plastocyanin, ferrodoxin and $\mathrm{NADP}^{+}$. Some heavy metals, such as $\mathrm{Hg}^{2+}, \mathrm{Cu}^{2+}, \mathrm{Cd}^{2+}$, $\mathrm{Zn}^{+}$and $\mathrm{Ni}^{2+}$, are known to substitute the central $\mathrm{Mg}^{2+}$ atom in the chlorophyll molecule, a process that lowers the fluorescence quantum yield and results in a shift in the fluorescence spectrum (Küpper et al. 1996). As heavy metal toxicity is generally considered to be dose-dependent, it could be assumed that exposure to higher concentrations or over longer periods should result in higher toxicity as stated by Baumann et al. (2009). Eklund and Kautsky (2003) and Baumann et al. (2009) have also reported that the effects of metal exposure on algae are species-specific and metal-specific, and that in some cases there can be seen an obvious relationship between internal metal contents and effects on chlorophyll fluorescence.

According to results of the present study, exposure to heavy metal ions has effects on pigmentation of different algae Therefore, from the results of this laboratory study, it can be concluded that both Ulva lactuca and Fucus vesiculosus are potential biomarkers as pigment changes are easy to detect.

\section{Acknowledgements}

The scholarship awarded by Vlaamse Interuniversitaire Raad (VLIR) from Flemish Interuniversity council to the first author to pursue Master degree in Ecological Marine Management in VUB University, Belgium is highly acknowledged as it provided the opportunity to conduct the current research. Professor E.I.L. Silva, Professor J.M.P.K. Jayasinghe and Professor Upali Amarasinghe are greatly appreciated for the support and guidance given in preparation of this manuscript. Two anonymous referees have given constructive comments on the manuscript.

\section{REFERENCES}

Baumann H.A., L. Morrison and D.B. Stengel 2009. Metal accumulation and toxicity measured by PAM-Chlorophyll fluorescence in seven species of marine macroalgae. Ecotoxicology and Environmental Safety 72: 1063-1075. doi:10.1016/j.ecoenv.2008.10.010

Bryan G.W. 1969. The absorption of $\mathrm{Zn}$ and other metals by the brown seaweed Laminaria digitata. Journal of Marine Biological Association United Kingdom, 49: 225-243. doi:https://doi.org/10.1017/S00253154000465 31

Bryan G.W. 1983. Brown seaweed, Fucus vesiculosus, and the gastropod, Littorina littoralis, as indicators of trace metal availability in estuaries. Science of the Total Environment 28: 91-104. doi:10.1016/S0048-9697(83)80010-2

Cairns Jr. J. and W.H. van der Schalie 1980. Biological monitoring, Part I-Early warning systems. Water Research 14(9): 1179-1196. doi:10.1016/0043-1354(80)90175-X

De Kock W.C. and K.J.M. Kramer 1994. Active biomonitoring $(\mathrm{ABM})$ by transition of bivalves molluscs. pp 51-84. In: K.J.M. Kramer (ed.), Biomonitoring of coastal waters and estuaries. CRC Press, Baton Rouge.

Eklund B.T. and L. Kautsky 2003. Review on toxicity testing with marine macroalgae and the need for method standardization-exemplified with copper and phenol. Marine Pollution Bulletin 46(2): 171-181. oi:http://dx.doi.org/10.1016/S0025326X(02)00225-4 
Fletcher R.L. 1991. Marine algae as bioassay test organism. pp. 111-131. In: P.D. Abel and V. Axiak (eds), Ecotoxicological and the Marine Environment. Ellis Horwood, New York.

Galloway T.S., R.C. Sanger, K.L. Smith, G. Fillmann, J.W. Readman, T.E. Ford and M.H. Depledge 2002. Rapid assessment of marine pollution using multiple biomarker and chemical immunoassays. Environmental Science and Technology. 36: 2219-2226. doi:10.1021/es010300w

Gaitán-Espitia J.D. 2011. Metabolic rates and primary productivity of the marine macroalgae Dictyopteris delicatula in Taganga Bay, Colombian Caribbean. Revista de Biología Marina y Oceanografía 46(1): 73-77. http://dx.doi.org/10.4067/S071819572011000100011

Kowalewska G. 1999. Phytoplankton-the main factor responsible for transport of polynuclear aromatic hydrocarbons from water to sediments in the Southern Baltic ecosystem. ICES Journal of Marine Science 56: 219-222. doi:10.1006/jmsc.1999.0607

Küpper H., F.C. Küpper and M. Spiller 1996. Environmental relevance of heavy metalsubstituted chlorophylls using the example of water plants. Journal of Experimental Botany 47: 259-266. doi:10.1093/jxb/47.2.259

Leal M.C.F., M.T. Vasconcelos Sousa-Pinto and I. Cabral J.P.S. 1997. Biomonitoring with benthic macroalgae and direct assay of heavy metals in seawater of the Oporto coast (North West Portugal). Marine Pollution Bulletin 34: 1006-1015. doi:10.1016/S0025326X(97)00112-4

Lei A-P., Y-S. Wong and N.F-Y. Tam 2002. Removal of pyrene by different microalgal species. Water Science and Technology 46(11-12): 195-201.

Lei A-P., Z-L. Hu, Y-S. Wong and N.F-Y. Tam 2007. Removal of fuoranthene and pyrene by different microalgal species. Bioresource Technology 98: 273-280. doi:10.1016/j.biortech.2006.01.012

Levine H.G. 1984. The use of seaweeds for monitoring coastal waters. pp. 189-210. In: Shubert, E.L. (ed.), Algae as Ecological Indicators. Academic Press, London.
Murray L.A., A. Raab, I.L. Marr and J. Feldmann 2003. Biotransformation of arsenate to arsenosugars by Chlorella vulgaris. Applied Organometalic Chemistry 17: 669-674. doi:10.1002/aoc.498

Okay O.S., Donkin, P., Peters, L.D. and D.R. Livingstone 2000. The role of algae (Isochrysis galbana) enrichment on the bioaccumulation of benzo[a]pyrene and its effects on the blue mussel (Mytilus edulis). Environmental Pollution 110: 103-113. doi:10.1016/S0269-7491(99)00282-1

Phillips D.J.H. 1990. Use of macroalgae and invertebrates as monitors of metal levels in estuaries and coastal waters Ch.6. pp. 81-99. In: Furness, R.W. and P.S. Rainbow (eds) Heavy Metals In the Marine Environment. CRC Press, Boca Raton

Prasad M.N.V. and K.Strzalka 1999. Impact of heavy metals on photosynthesis. pp. 117-138. In: Prasad, M.N.V. and J. Hagemeyer (eds), Heavy Metal Stress in Plants-from Molecules to Ecosystems. Springer, Berlin.

Söderlund S., A. Forsberg and M. Pedersén 1988. Concentration of cadmium and other metals in Fucus vesiculosus and Fontinalis dalecarlica from the northern Baltic Sea and the southern Bothnian Sea. Environmental Pollution 51: 197-212. doi:10.1016/0269-7491(88)90261-8

Stewart P.M. 1995. Use of algae in aquatic pollution assessment. Natural Areas Journal 15(3): 234239.

Torres M.A., M.P. Barros, S.C.G. Campos, E. Pinto, S. Rajamani, R.T. Sayre and P. Colepicolo 2008. Biochemical biomarkers in algae and marine pollution: A review. Ecotoxicology and Environmental Safety 71: 1-15. doi: 10.1016/j.ecoenv.2008.05.009

Wang J.S., H.N. Chou, J-J. Fan and C.M. Chen 1998. Uptake and transfer of high PCB concentrations from phytoplankton to aquatic biota. Chemosphere 36: 1201-1210. doi:10.1016/S0045-6535(97)83101-3

Whitton B.A. and M.G. Kelly 1995. Use of algae and other plants for monitoring rivers. Australian Journal of Ecology 20: 45-56. doi:10.1111/j.1442-9993.1995.tb00521.x 